\title{
太陽観測による正午位置決定に就て
}

\section{On the Determination of Noon Position \\ by the Observation of the Sun}

\author{
本岩節 (北大水喾学部)
}

Abstract

In the case of the determination of noon position by both ante-meridian and noon sights by the sun, it is generally considered to be best that lst sight should be observed about 9 a. m., or when its zimuth is near $90^{\circ}$

However, the former is based upon customary practice, which the latter deals with both of two position lines equally precise, without considering the error due to transferring the position line. Hence, each of them is not theoretical.

In this papers, the writer treated of the probable best opportunities to observe 1 st sight according to various combinations of latitude and declination.

Table I shows the values of the best opportunities to observe lst sights.

Fig. 2 shows each reliability of ship positions obtained by both observations at the best oppprtunities to observe 1 st sights and at noon, by which we can confirm that the case when latitude and declination are of same sign is better then they are of cointrary signs.

Fig. 3 shows the azimuths of the sun at the best oppertunities to observe 1 st sights, which generally lies between $50^{\prime}$ and $70^{\circ}$, accordingly we cannot say easily that it is preferable to observe 1 st sight when its azimuth is near $90^{\circ}$.

In this papers, the writer dealt with standard error of ecch observation as 0.74 , and an error of estimated position as $0.74 \sqrt{t}$. ( $t:$ hour), which under various circumstances are not free from some differences are hardly avoided in comparison with the valies of the table I.

However, the writer hopes herewith that it may become a leading mark to know the best opportunity to observe 1 st sight by the sun.

\section{1. 緒}

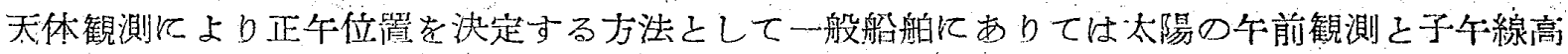

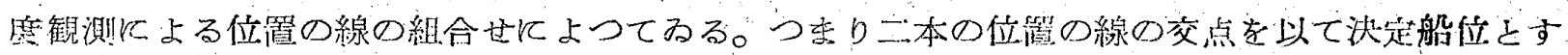
るのである。

二本の位置の線と上る船位の確率密度々位置の線が淔交するとき最大てあるから最良の組合せ

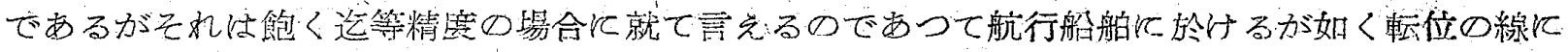

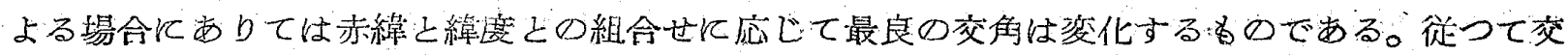




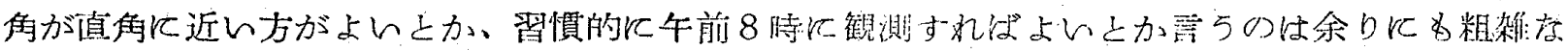

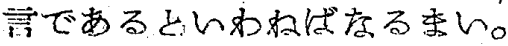

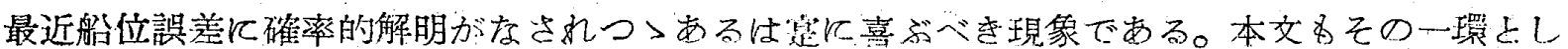

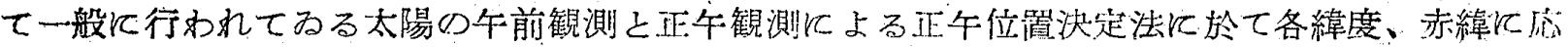

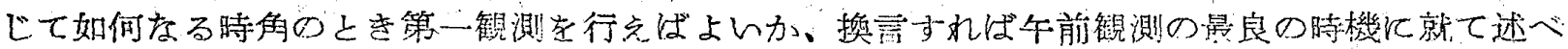

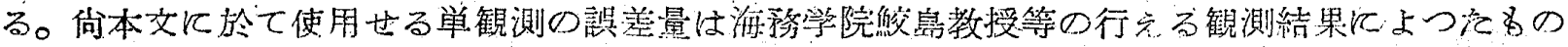
であり記して同氏等に謝意を表する，。

\section{2. 二本の位置の線の交点の確率密度}

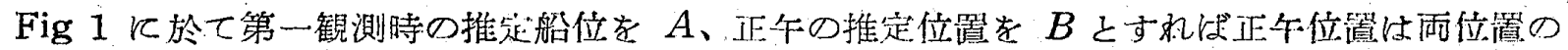
線の交点 0 として決定される。今二本の位置の線を，X、Y，之の交角を $\varphi$ とし、 $X 、 Y$ の俱営

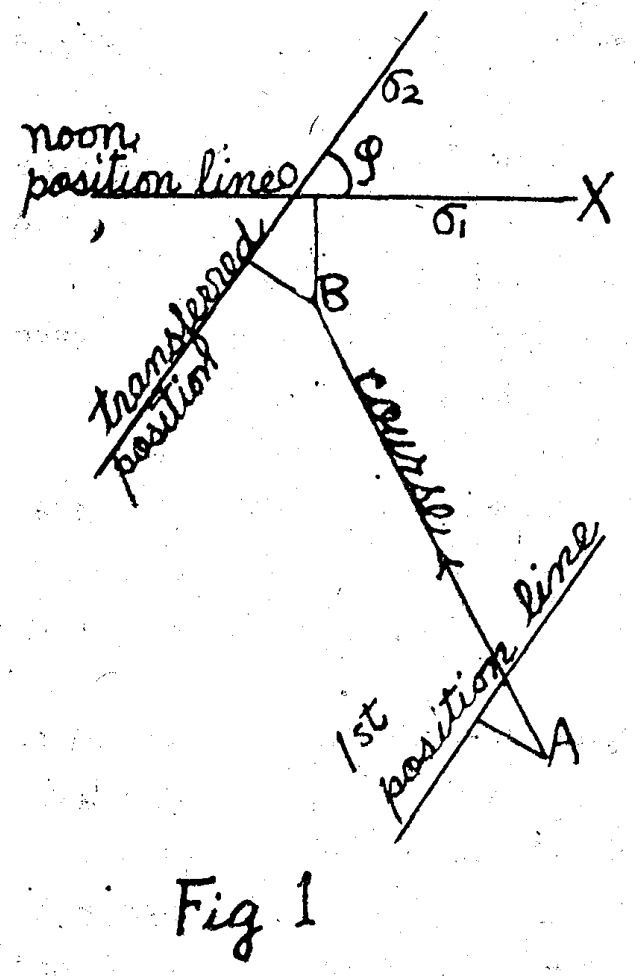

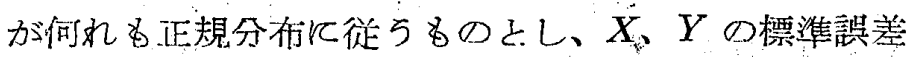
(即ち实測値の標準偏差) を夫ァ $\sigma_{1} 、 \sigma_{2}$ とすれ代

$X$ の確率密度要数忹

$$
\sigma_{x}=\frac{\sigma_{2}}{\sin \phi}, \sigma_{y}=\frac{\sigma_{1}}{\sin \phi}
$$

$$
f_{1}(x)=\frac{\sin \varphi}{\sqrt{2 \pi} \sigma_{2}} e^{-\sin ^{2} \phi \frac{x^{2}}{2 \sigma_{2}{ }^{2}}}
$$

$Y$ の確率密度圂数は

$$
f_{2}(y)=\frac{\sin \varphi}{\sqrt{2 \pi} \sigma_{1}} e^{-\sin ^{2} \phi \frac{y^{2}}{2 \sigma_{1}{ }^{3}}}
$$

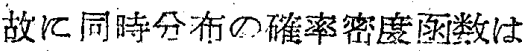

$$
\frac{\sin \phi}{2 \pi \sigma_{1} \sigma_{2}} e^{-\sin ^{2} \phi\left(\frac{y^{2}}{2 \sigma_{1}^{2}}-\frac{x^{2}}{2 \sigma_{2}^{2}}\right)}
$$

である。従つて交点 0 の磷率密度俚上記の probability density function 飞於て $x=0, y=0$ と怙けば $k=$ $\frac{\sin \varphi}{2 \pi \sigma_{1} \sigma_{2}}[k ;$ 形乘密度 $]$ である。

\section{3. 千 前 観 測 の 最適機}

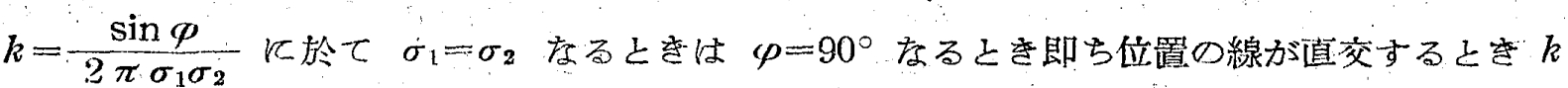
岋最大であることは容易に元える。換言すれば位置の線の精度が等しんとを二回の観測により観

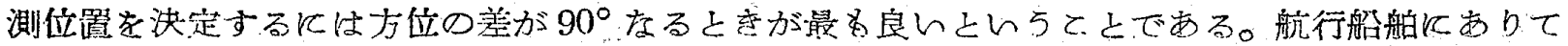

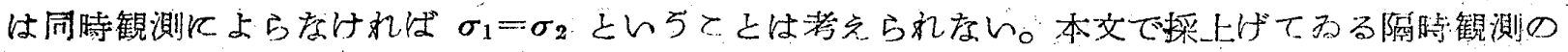

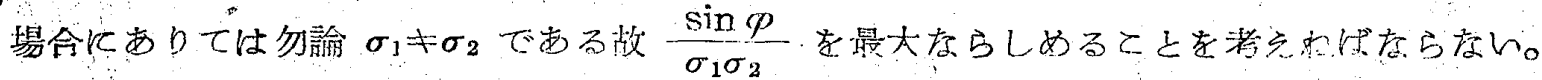

とつに単観測の慓準部差 $\sigma_{1}=0.74$

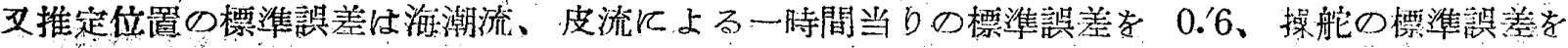

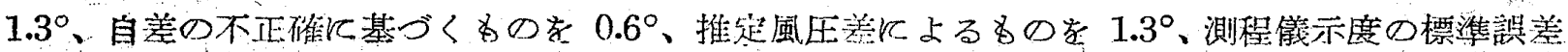

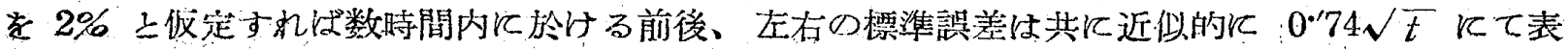


わされる。(但し $t$ は航走時間)

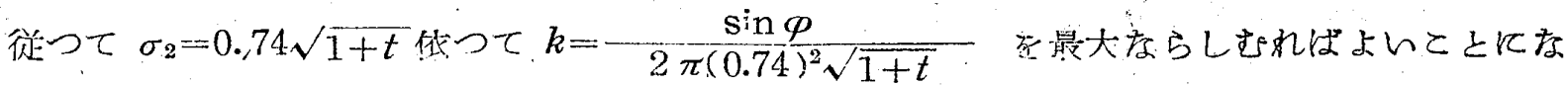

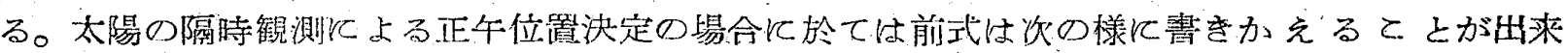
る。

$$
k=c \frac{\sin Z}{\sqrt{1+h}}
$$

\section{c.........常数}

$Z \cdots \cdots \cdots . .1$ st sight $飞$ 於ける太陽の方位

\section{$h \cdots \cdots \cdot \cdot 1$ st sight 飞於ける太陽の時角（時）}

これた最大ならしめるとは $h$ が小で $Z$ が大であれば問題はないが $h$ と $Z$ との間には之に

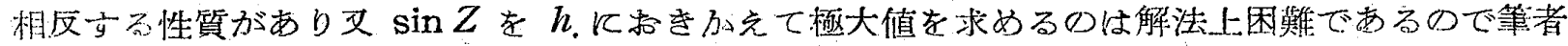

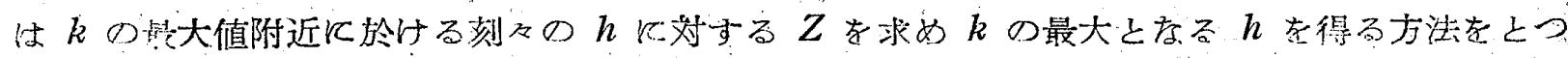

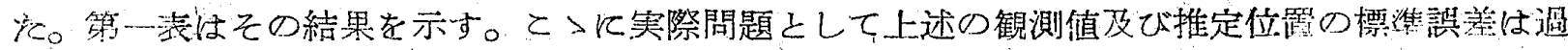

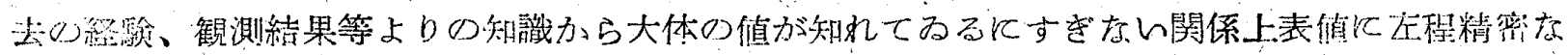

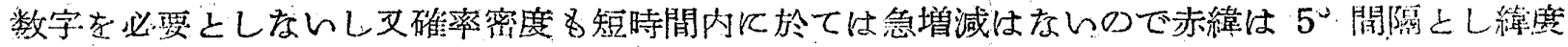
は表使用上便利な㥞に $1^{\circ}$ 間隔とした。表使用に当つて赤絙の中間值に対じては目算に上つて結

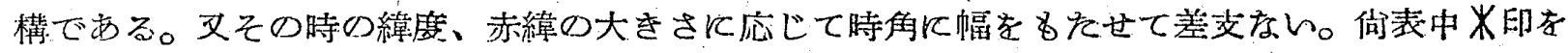
附せるものより高緯度のものは最避機の計算值が日出前になるからかつる場合には日出後適当存 高度に達するのを待つて観測すればよん。

\section{Fig 2}

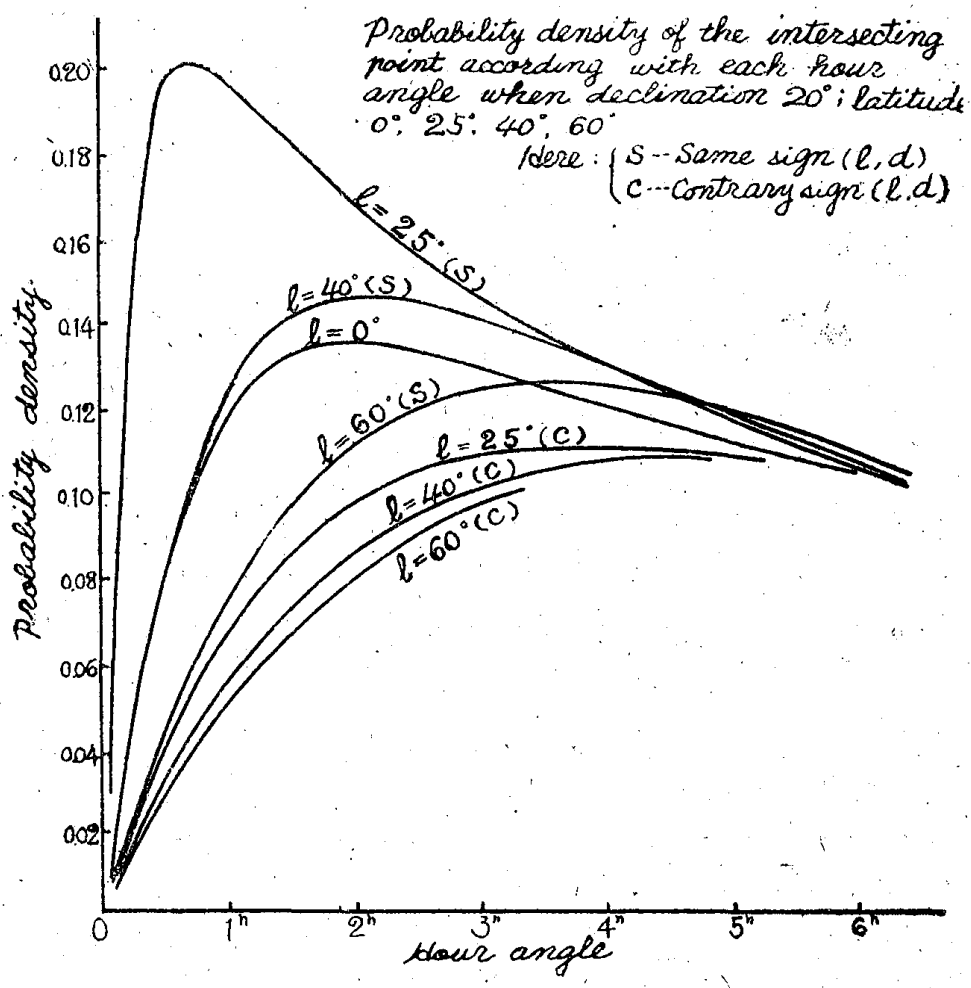




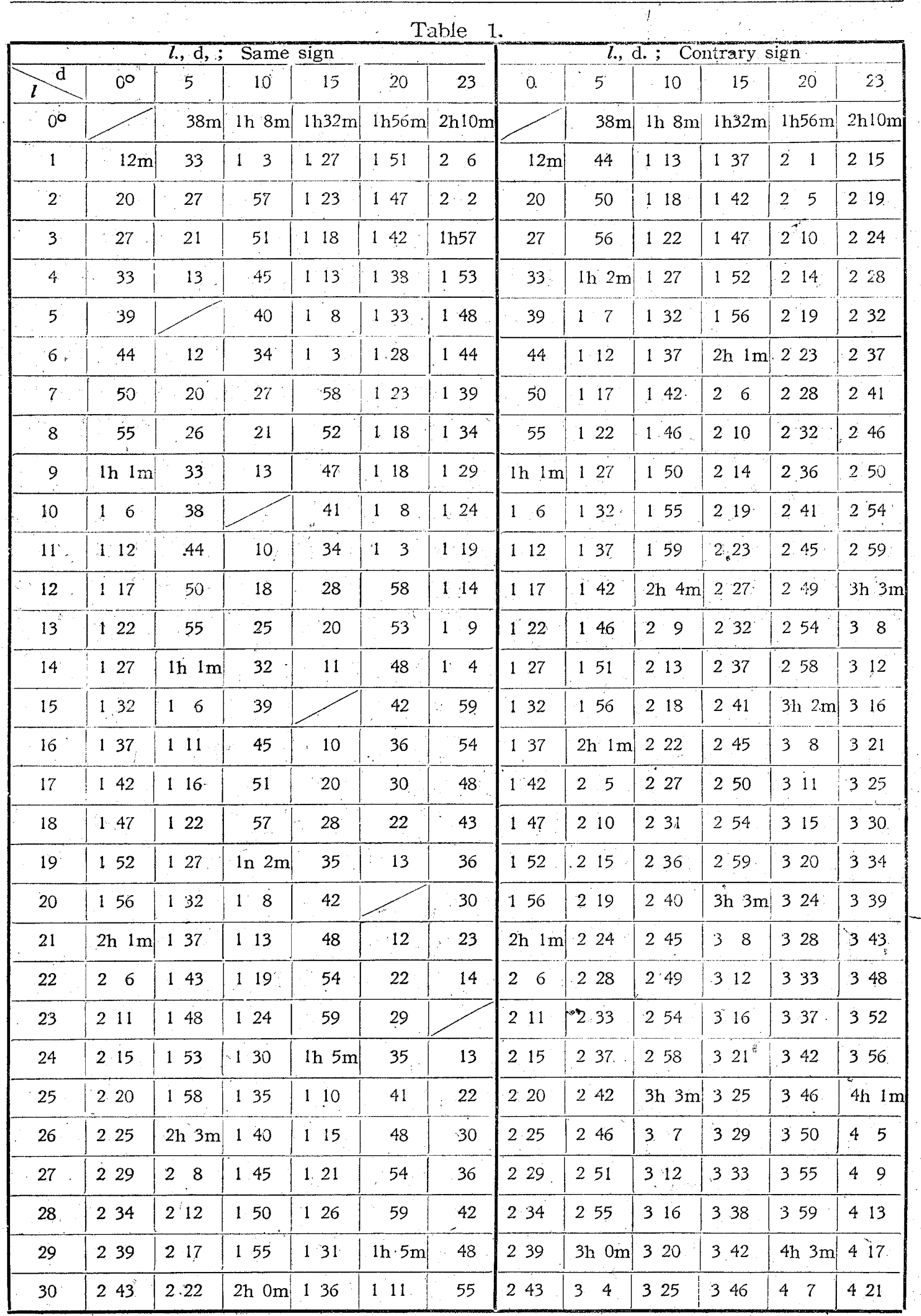


Table 1

\begin{tabular}{|c|c|c|c|c|c|c|c|c|c|c|c|c|}
\hline \multicolumn{7}{|c|}{ l., d. ; Same sign } & \multicolumn{6}{|c|}{ l., d, ; Contrary sign } \\
\hline$l d$ & 00 & 5 & 10 & 15 & 20 & 23 & 0 & 5 & 10 & 15 & 20 & 23 \\
\hline 31 & 247 & 226 & 25 & 141 & 117 & $1 \mathrm{~h} \operatorname{lm}$ & 247 & 38 & 329 & 350 & 411 & 425 \\
\hline 32 & 252 & 231 & 210 & 147 & 122 & 17 & 252 & 312 & 333 & 354 & 415 & 430 \\
\hline 33 & 256 & 235 & 215 & 152 & 128 & 113 & 256 & 316 & 337 & 358 & 419 & 434 \\
\hline 34 & $3 \mathrm{~h} 0 \mathrm{~m}$ & 240 & 219 & $157^{\circ}$ & 133 & $1 \cdot 18$ & $3 \mathrm{~h} \mathrm{Cm}$ & 321 & 3.42 & $4 \mathrm{~h} 2 \mathrm{~m}$ & 423 & 438 \\
\hline 35 & 34 & 244 & 224 & $2 \mathrm{~h} 2 \mathrm{~m}$ & 139 & 124 & 3.4 & 325 & 346 & 46 & 4.27 & 4.42 \\
\hline 36 & 38 & 248 & 229 & 27 & 145 & 130 & 38 & $3 \approx 9$ & 350 & 410 & 431 & 4.45 \\
\hline 37 & 312 & 253 & 233 & 212 & 150 & 135 & 312 & 333 & 354 & 413 & 434 & $* 449$ \\
\hline 38 & 3.16 & 257 & 237 & 217 & 155 & 141 & 316 & 336 & 358 & 417 & 438 & 452 \\
\hline 39 & 320 & $3 \mathrm{~h} 1 \mathrm{~m}$ & 242 & $221:$ & $2 \mathrm{~h} 0 \mathrm{~m}$ & 146 & 320 & 340 & $4 \mathrm{~h} \mathrm{~lm}$ & 420 & 441 & 455 \\
\hline 40 & 324 & 35 & 246 & 226 & 26 & 152 & 324 & 344 & 4.5 & 423 & 444 & 458 \\
\hline 41 & 328 & 39 & 250 & 230 & 211 & 157 & 328 & 347 & 48 & 426 & 448 & $5 \mathrm{~h} \ln$ \\
\hline 42 & 332 & 313 & 255 & 235 & 216 & $2 \mathrm{~h} 2 \mathrm{~m}$ & 332 & 351 & 412 & 429 & 450 & \\
\hline 43 & 335 & 318 & 259 & 240 & 221 & 28 & 335 & 354 & 415 & 432 & 453 & \\
\hline 44 & 339 & 321 & $3 \mathrm{~h} 3 \mathrm{~m}$ & $2 \cdot 44$ & 226 & 213 & 339 & 357 & 418 & 435 & 455 & \\
\hline 45 & 342 & 325 & 37 & 249 & 231. & 218 & 342 & $4 \mathrm{~h} 0 \mathrm{~m}$ & 420 & 438 & 457. & \\
\hline 46 & 346 & 3.29 & 311 & 253 & 235 & 223 & 346 & 43 & $4 \cdot 22$ & 440 & 459 & 510 \\
\hline 47 & 349 & 332 & 315 & 257 & 240 & 228 & 349 & 46 & 425 & 443 & $5 \mathrm{~h} 1 \mathrm{~m}$ & $\begin{array}{ll}512 \\
12\end{array}$ \\
\hline 48 & 352 & 3.36 & 319 & $3 \mathrm{~h} 2 \mathrm{~m}$ & 245 & 233 & 352 & 49 & 427 & 445 & 52 & 513 \\
\hline 49 & 3.55 & 339 & 323 & 36 & 249 & 237 & 355 & 412 & 429 & 447 & 54 & 515 \\
\hline 50 & 358 & 342 & 326 & 3.10 & 254 & 242 & 358 & 4.15 & 431 & $* 4 \quad 49$ & 55 & 516 \\
\hline 51 & $4 \mathrm{~h} 1 \mathrm{~m}$ & 346 & 330 & 314. & 258 & 246 & $4 \mathrm{~h} \mathrm{~lm}$ & 417 & 433 & 451 & 56 & 517 \\
\hline .52 & 44 & 349 & 334 & 318 & $3 \mathrm{~h} 2 \mathrm{~m}$ & 251 & 44 & 419 & 435 & 452 & 57 & 518 \\
\hline 53 & 47 & 352 & 337 & 3.22 & 36 & 255 & 47 & 421 & 437 & 453 & 58 & 519 \\
\hline 54 & 49 & 355 & 341 & 3.26 & 310 & $3 \mathrm{~h} \mathrm{Om}$ & 49 & 423 & 439 & 454 & 59 & 519 \\
\hline 55 & 412 & 358 & 344 & 330 & 314 & 34 & 412 & 425 & 441 & 455 & 510 & 520 \\
\hline 56 & 414 & $4 \mathrm{~h} 1 \mathrm{~m}$ & 348 & 333 & 318 & 38 & 414 & 427 & 442 & 456 & 510 & 5. 20 \\
\hline 57 & 417 & 43 & 351 & 337 & 322 & 313 & 417 & 429 & 443 & 457 & 510 & 520 \\
\hline 58. & 419 & 46 & 353 & 340 & 326 & 317 & 419 & 431 & 444 & 458 & 510 & 520 \\
\hline 59 & 421 & 48 & 356 & 343 & 330 & 321 & 421 & 432 & 445 & 459 & 511 & 520 \\
\hline 60 & 422 & 410 & 358 & 346 & 334 & 325 & 422 & 433 & 446 & 459 & 511 & 520 \\
\hline
\end{tabular}


一例として赤䋨が $20^{\circ} 、$ 緯度が $0^{\circ} 、 25^{\circ} 、 40^{\circ} 、 60^{\circ}$ の場合考考充就ば最適機の時角は夫か

$1 \mathrm{~h} 56 \mathrm{~m} 、 \quad 41 \mathrm{~m}$ (Same sign) $\quad 2 \mathrm{~h} 6 \mathrm{~m}(\mathrm{~S}) 4 \mathrm{~h} 34 \mathrm{~m}(\mathrm{~S})$

となるが $\boldsymbol{k}$ 值の変化の状態を graph に画いてみを。Fig 2 が即ちそれである。同図を通して 最邀機として許容さるべき時角の幅がよく判ると思ら。

\section{4. 最適機の比較及方位}

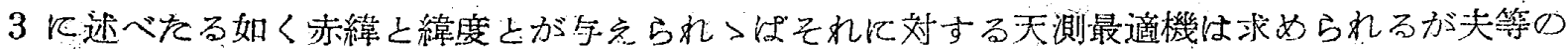
最適機に観測した場命決定船位の確らしさは $k$ の值によつて勿論異る。つまり $k$ が大をくなれ、 忪船位の確らしさは増す。換言すれば䛊差界は当然小之索るので行船上は $k$ の值は可及的大な

Fig 3

Probability density of the intersecting pount of the two position lines gotten from 1st sight. at the best time and nom sight. The sign... shous the probability density in the combination of sun sise and noon

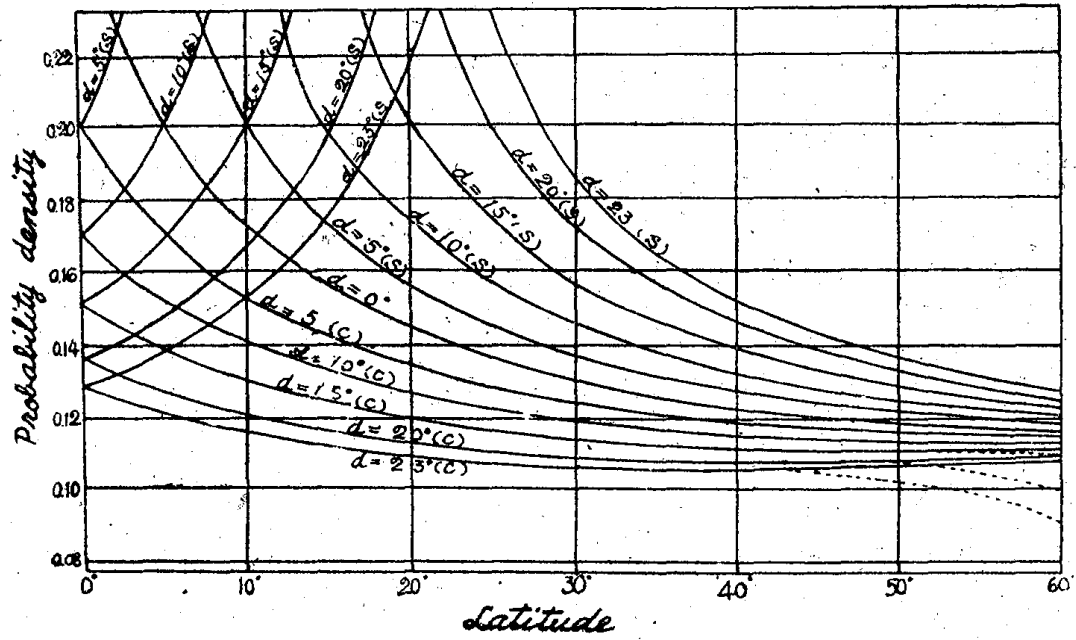

Fig 4

Agimuth of the sun at the best time to ohserve 1st sight.

The sign -.. shows the agimuah of sun rise

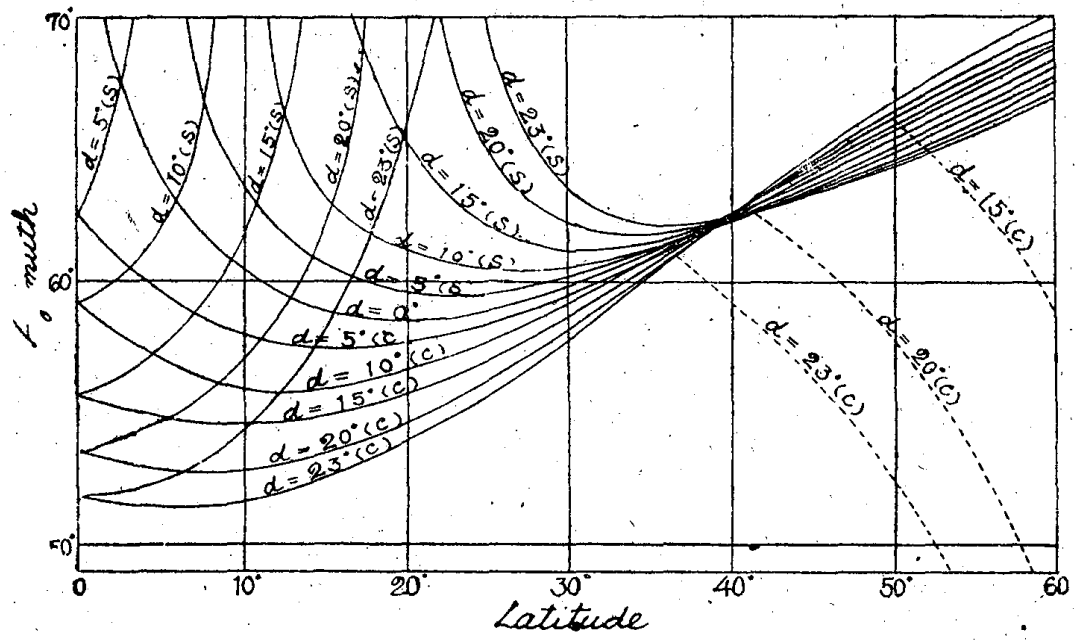


らしめたんのであるが $k$ の最大值は前述の如く緯度、赤緯によつて決定されるるので如何とる出 来をん。然し乍ら与えられを条件下に於て最良の時機を見出すことは航海上必要なること論を俟 たない。Fig 3 は各緯度、赤緯に対する最適機観測を正午観測上り得をる二本の位置の線の交点

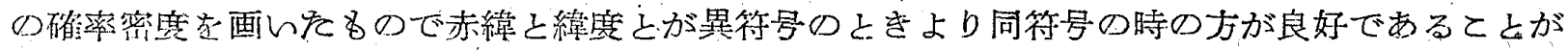
判る又 Fig 4 は最適機儿於ける太陽の方位を示す。同図に見る如く最適機の方位は大体 $50^{\circ}$ か ら $70^{\circ}$ め間に位するすので漫然と $90^{\circ}$ K近ん方がよんと言らと上は出来ない。

\section{5. 結 言}

船位の確らしさは位置の線の数が多ければ多い程大となるととは既に知られてるるところであ る。その点から言えば午前之正午の二国の観測では条件が悪いと言える。てれは一つには中太

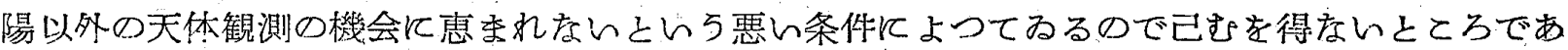
る。又船位決定の点から見れば他に方法は考元られるが船船の習慣として正午位置に重点をおい てみる関係上従来の午前亡正午観測の組命せの吟味、検討を行つた。

爻本交中篻観測の標準鿁差を 0.'74 として扱つたがをの值は観測者個及に就て異ること勿論で

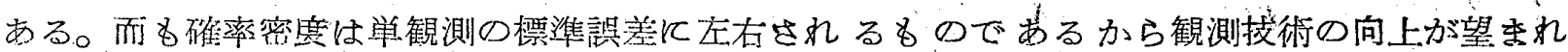
る。それと他の一つは本文に述べをるは推定船位の標準愦差考 $0,74 \sqrt{\boldsymbol{t}}$ として取扱つてわるの

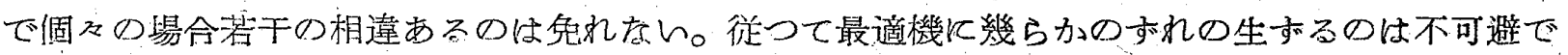
あるが天測時機の基準となれば幸基である。決定船位に就て適当な愦差界を考え航海の万全を 期するとと航海者として一層大切な事であると思ら。 